Check for updates

Cite this: J. Mater. Chem. B, 2019, 7, 7783

Received 11th September 2019 Accepted 13th November 2019

DOI: $10.1039 / c 9 t b 01985 e$

rsc.li/materials-b

\section{Polyphosphazene-based nanocarriers for the release of agrochemicals and potential anticancer drugs $\dagger$}

\author{
Javier Pérez Quiñones, (D) *a Aitziber Iturmendi, (D) ${ }^{a}$ Helena Henke, (D) ${ }^{a}$ \\ Cornelia Roschger, ${ }^{b}$ Andreas Zierer ${ }^{\mathrm{b}}$ and Oliver Brüggemann ${ }^{\mathrm{a}}$
}

\begin{abstract}
The synthesis and characterisation of novel polyphosphazene nanocarriers, based on hydrophilic polyalkylene oxide Jeffamine M1000 and hydrophobic steroids with a glycinate linker for pH-controlled release of diosgenin and two brassinosteroids (DI31 and S7) with agrochemical and potential anticancer activity, is hereby described. Polyphosphazenes carrying approximately 17 wt\% of DI31 or S7 selfassembled in water to form 120-150 nm nanoaggregates, which showed an excellent plant growth effect on radish cotyledons due to sustained delivery of approximately $30 \%$ of the agrochemicals after 4 days. Cytotoxic evaluation showed that all polymers carrying steroids and Jeffamine M1000 resulted in strong to moderate toxicity to MCF-7 cancer cells and were non-toxic to primary human lung fibroblast cells at 0.1 to $0.025 \mathrm{mg} \mathrm{mL}^{-1}$. Thus, DI31 and S7 bearing polymers applied at $10^{-4}$ to $10^{-6} \mathrm{mg} \mathrm{mL}^{-1}$ for delivery of recommended DI31 or S7 quantities to crops should be harmless to humans. Particularly, DI31 and S7 bearing polymers with strong cytotoxicity on MCF-7 and non-toxicity on primary human lung fibroblasts, good cell uptake after 6 hours, proper hydrodynamic sizes between 100 and $200 \mathrm{~nm}$, and slow sustained release of cytotoxic drugs (DI31, S7) in acidic conditions might potentiate their accumulation in cancer tissues with good antitumour effects and minor side effects. These results demonstrated that preparation of brassinosteroid bearing polymers is a promising strategy for the preparation of better agrochemicals with reduced pollutant impact on sustainable agriculture and potential anticancer formulations based on analogues of brassinosteroids.
\end{abstract}

\section{Introduction}

Brassinosteroids (BR), a naturally occurring steroid plant hormone group found in all vegetal organs, regulate plant growth and development by eliciting several physiological effects in combination with other phytohormones. ${ }^{1,2}$ These phytohormones promote xylem differentiation, stem elongation, leaf bending, epinasty, and biosynthesis of nucleic acids, proteins and ethylene, regulate assimilation and allocation of carbohydrates and response mechanisms of plants to biotic and abiotic stress and activate photosynthesis. ${ }^{3-5}$ The content of BR in plants ranges from $10^{-1} \mathrm{nmol} \mathrm{g}^{-1}$ to $10^{-7} \mathrm{nmol} \mathrm{g}{ }^{-1}$, being 100 times smaller than other phytohormones. ${ }^{6,7} \mathrm{BR}$ and some synthetic

\footnotetext{
${ }^{a}$ Institute of Polymer Chemistry (ICP), Johannes Kepler University Linz, Altenberger Str. 69, 4040 Linz, Austria. E-mail: javenator@gmail.com; Fax: +43 73224689081; Tel: +4373224689076

${ }^{b}$ Johannes Kepler University Linz, Kepler University Hospital GmbH,

Department for Cardiac-, Vascular- and Thoracic Surgery, Altenberger Str. 69, 4040 Linz and Krankenhausstrasse 9, 4020 Linz, Austria

$\dagger$ Electronic supplementary information (ESI) available: Additional polymer characterisation data. See DOI: 10.1039/c9tb01985e
}

analogues of brassinosteroids are widely used at concentrations of 5 to $100 \mathrm{mg} \mathrm{ha}{ }^{-1}$ as agrochemicals and pesticides, with a significant improvement in the quality and efficiency of crops. ${ }^{8,9}$ Particularly promising results are observed when the synthetic analogues of brassinosteroids DI31 and S7 are applied at 10-20 $\mathrm{mg} \mathrm{ha}^{-1}$ as agrochemicals, with demonstrated increases of $5-30 \%$ of crop yields. ${ }^{10,11}$ However, rapid metabolism of BR-based agrochemicals limits the efficacy of DI31 and S7, which results in periodic foliar applications being required to achieve their known benefits. ${ }^{11}$ The hydrophobicity of DI31 and S7 also complicates their application in agriculture, it being necessary to prepare their commercial formulations as emulsions containing 100 ppm of DI31 in 50 vol\% water/ethanol and surfactants (Biobras-16), with limited stability. ${ }^{12,13}$ To avoid the rapid metabolism of DI31 or S7 and provide a constant supply of these compounds with increased solubility in water, they would be incorporated in different polymer-based systems such as micelles, nanoparticles, vesicles, dendrimers or other carriers that protect them and assure controlled release for a longer period of time. ${ }^{14,15}$ However, relatively fewer drug delivery systems have been aimed at sustained release of agrochemicals 
than pharmaceuticals. ${ }^{16}$ In this sense, an ideal drug delivery system for application in agriculture should provide sustained release of the agrochemical, achieving a high drug loading with retained activity, good solubility and stability in water under normal usage conditions ( $\mathrm{pH} 7.0,25^{\circ} \mathrm{C}$ ), together with proper degradation and no toxicity of the polymer matrix and its metabolites in plants and animals. ${ }^{17,18}$ Hence, polyphosphazenes, a group of degradable synthetic polymers with highly tuneable composition and properties, appear to be promising candidates to this end. On the other hand, diosgenin was chosen as a model-drug to assess the $\mathrm{pH}$-promoted delivery of steroids from polyphosphazene nanocarriers. ${ }^{19}$ This steroid sapogenin is a cheap substrate widely used for synthesis of steroids, corticosteroids and the agrochemical DI31, ${ }^{20}$ providing a suitable model for the bulky steroid substituents on polyphosphazenes. Diosgenin itself has shown good antidiabetic, hypocholesterolemic, antithrombotic and anticancer activity, but very low aqueous solubility and reduced oral bioavailability limit its medical applications. ${ }^{19,21}$ Similarly, some brassinosteroids and synthetic analogues of brassinosteroids have displayed potent antiproliferative effects on different cancer cells with reduced haemolysis and negative effects on non-cancer cells. ${ }^{22,23}$ This is the reasoning behind designing an efficient polyphosphazene-based drug delivery system for diosgenin and brassinosteroids.

Polyphosphazenes, also named poly(organo)phosphazenes, are organic-inorganic hybrid polymers with a characteristic $\left[-\mathrm{R}_{2} \mathrm{P}=\mathrm{N}-\right]$ repeating unit in which different nucleophiles attached to the phosphorus atom tailor the properties of the polymer. $^{24,25}$ Then, different polyphosphazenes have been synthesised for wide diverse applications such as tissue engineering and drug delivery agents in biomedicine,${ }^{25-34}$ catalysts, ${ }^{35}$ flame retardants, ${ }^{36}$ high performance polymers ${ }^{37}$ and other materials. $^{38,39}$ Polyphosphazenes are particularly attractive since their properties, architectures, functionality and degradability can be fine-tuned by precise control of the polymer composition and synthetic pathway (degree of polymerisation, distribution and ratio of hydrophobic/hydrophilic substituents, structure, etc. .). ${ }^{24-38}$ Another advantage of the application of polyphosphazene-based biomaterials is that they degrade to phosphates and ammonium salts alongside the organic substituents, thus being benign degradation products if innocuous substituents have been selected..$^{25,27,38}$ Therefore, smartly designed polyphosphazenes carrying brassinosteroids might fit the requirements to sustainably deliver agrochemicals once applied to plants with minimized environmental impact and increased plant growth effect.

In this research, five polyphosphazene-based nanocarriers for delivery of diosgenin and two brassinosteroids (DI31 and S7) with agrochemical and potential anticancer activity were synthesised by living cationic polymerisation of $\mathrm{Cl}_{3} \mathrm{PNSiMe}_{3}$ to obtain poly(dichloro)phosphazene, which was further functionalised via post-polymerisation substitution with the steroids and hydrophilic Jeffamine M1000. Polyphosphazenes carrying diosgenin were synthesised with two degrees of polymerisation and steroid content to optimize the synthesis of the polymers, to study the effect of the average chain length and chemical composition on the nanoaggregates' hydrodynamic diameters and drug release behaviour. Sustained release of diosgenin from the nanocarriers in acidic medium via hydrolysis of ester bonds encouraged us to prepare pH-labile polyphosphazenes with DI31 and S7 for agrochemical applications. Controlled delivery of covalently linked DI31 and S7 from their nanocarriers increased their plant growth stimulant activity as assessed using in vitro radish cotyledon bioassay. Further, the cytotoxicity of all polymers to MCF-7 cancer cell line and primary human lung fibroblast cells was evaluated.

\section{Materials and methods}

\section{Materials}

An amine capped polyetheramine copolymer (PEO-PPO- $\mathrm{NH}_{2}$ ) with an $M_{\mathrm{n}}$ of $1000 \mathrm{~g} \mathrm{~mol}^{-1}$ and an ethylene oxide/propylene oxide ratio of 19/3, tradename Jeffamine M1000, was donated by Huntsman Performance Products and used as received. The diosgenin $[(25 R)-5 \text {-spirosten-3 } \beta \text {-ol }]^{40}$ and synthetic analogues of

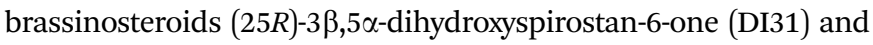
$(22 R, 23 R)$-22,23-epoxy-3 $\beta, 5 \alpha$-dihydroxystigmastan-6-one (S7) were kindly supplied by the University of Havana, Cuba. Triethylamine was distilled and stored over molecular sieves under argon. All other chemicals and solvents were purchased from Sigma-Aldrich and used without prior purification. All glassware was dried overnight in an oven at $120{ }^{\circ} \mathrm{C}$ prior to use. Spectra/Por 3 cellulose dialysis membranes (Spectrum Laboratories Inc., CA, USA) with a molecular weight cut off (MWCO) of $3.5 \mathrm{kDa}$ were used for purification of the synthesised polymers.

\section{Synthesis of steroid-glycine-Boc}

The synthesis of steroid-glycine-Boc and deprotected steroidglycine- $\mathrm{NH}_{2}$ (diosgenin-glycine- $\mathrm{NH}_{2}$ (1), DI31-glycine- $\mathrm{NH}_{2}$ (2) and $\mathrm{S} 7$-glycine- $\mathrm{NH}_{2}$ (3)) was carried out as previously reported, with minor modifications. ${ }^{26,27}$ The preparation of diosgenin glycinate is briefly described in the ESI. $\dagger$

\section{Synthesis of monomer trichlorophosphoranimine $\left(\mathrm{Cl}_{3} \mathrm{P}=\mathrm{N}-\mathrm{Si}\left(\mathrm{CH}_{3}\right)_{3}\right)$}

The monomer $N$-(trimethylsilyl)-trichlorophosphoranimine $\left(\mathrm{Cl}_{3} \mathrm{P}=\mathrm{N}-\mathrm{Si}\left(\mathrm{CH}_{3}\right)_{3}\right)$ was synthesised according to a reported procedure with slight modifications $(\mathrm{ESI} \dagger)^{38,41}$

\section{Synthesis of the polymers}

The synthesis of the poly(dichloro)phosphazene precursor was conducted via living cationic polymerisation of monomer trichlorophosphoranimine with triphenylphosphine dichloride. $^{24,28,30,38}$ The synthesis of polymer P1 is described in detail in the ESI. $\dagger$ For polymers P2-P6 the ratio of monomer to initiator, and the ratio of substituent steroid to Jeffamine M1000 were adjusted differently (Table 1). All reactions were performed in a glovebox under an inert atmosphere.

\section{In vitro drug release studies}

The in vitro release studies of diosgenin, DI31 and S7 were performed in phosphate buffered saline (PBS, $\mathrm{pH}$ 6.0) solution 
Table 1 Composition, yield and molecular weight of polymers P1-P6

\begin{tabular}{llllllll}
\hline Sample & I:M & DP & S:J & Y $(\%)$ & $M_{\mathrm{n}}^{\text {Tht }}\left(\mathrm{kg} \mathrm{mol}^{-1}\right)$ & $M_{\mathrm{n}}^{\exp }\left(\mathrm{kg} \mathrm{mol}^{-1}\right)$ & $\Xi^{\text {exp }}$ \\
\hline P1 & $1: 25$ & $23^{\mathrm{a}}$ & $1: 1$ & 37 & 38 & 10 & 1.37 \\
P2 & $1: 25$ & $22^{\mathrm{b}}$ & $1: 2$ & 38 & 42 & 15 & 1.47 \\
P3 & $1: 50$ & 34 & $1: 1$ & 35 & 76 & 12 & 1.31 \\
P4 & $1: 25$ & 20 & $1: 2$ & 34 & $43^{\mathrm{c}}$ & 14 & 1.35 \\
P5 & $1: 25$ & $22^{\mathrm{b}}$ & $1: 2$ & 30 & $43^{\mathrm{c}}$ & 13 & 1.50 \\
P6 & $1: 25$ & $23^{\mathrm{a}}$ & $0: 2$ & 49 & 51 & 11 & 1.44
\end{tabular}

Initiator to monomer ratio feed composition (I:M). Degree of polymerisation estimated by ${ }^{1} \mathrm{H}$ NMR (DP). Steroid to Jeffamine M1000 ratio feed composition $(\mathrm{S}: \mathrm{J})$. Theoretical number average molecular weight $\left(M_{\mathrm{n}}^{\text {Tht }}\right)$. Experimental number average molecular weight and polydispersities measured by GPC against polystyrene standards $\left(M_{\mathrm{n}}^{\exp }, \Xi^{\exp }\right)$.

at $25{ }^{\circ} \mathrm{C}$. To this end, $2.0 \mathrm{~mL}$ of polymers P1-P5 $\left(2.5 \mathrm{mg} \mathrm{mL}{ }^{-1}\right)$ in PBS at pH 6.0 were placed in dialysis cups (MWCO $3.5 \mathrm{kDa}$, Slide-A-Lyzer mini dialysis devices, ThermoScientific, USA) and immersed in $40 \mathrm{~mL}$ of the release medium (PBS, pH 6.0) at $25{ }^{\circ} \mathrm{C}$ and stirred at $150 \mathrm{rpm}$. The release medium was replaced every required time point, and analysed with UV spectroscopy (diosgenin $\lambda_{\mathrm{em}}=280 \mathrm{~nm}$, DI31 and S7 $\lambda_{\mathrm{em}}=300 \mathrm{~nm}$ ). Release experiments were conducted in triplicate. Calibration curves of the steroids (ESI $\dagger$ ) allowed quantification of the delivered drug (diosgenin $\varepsilon_{280}=688 \mathrm{M}^{-1} \mathrm{~cm}^{-1}$, DI31 $\varepsilon_{300}=1693 \mathrm{M}^{-1} \mathrm{~cm}^{-1}$, S7 $\left.\varepsilon_{300}=1290 \mathrm{M}^{-1} \mathrm{~cm}^{-1}\right){ }^{42}$

\section{In vitro agrochemical tests}

The agrochemical bioactivity as a plant growth enhancer of the synthesised polymers carrying the brassinosteroid analogues DI31 and S7 (P4 and P5) was evaluated in vitro on radish (Raphanus sativus) plants. The increased weight of radish cotyledons was used to assess the agrochemical activity of the tested compounds. Radish seeds were sterilised with sodium hypochlorite solution prior to germination on wet filter paper in the dark at room temperature for 3 days. ${ }^{43}$ Then, the hypocotyls were discarded and the cotyledons weighed and transferred to Petri dishes with $5 \mathrm{~mL}$ aqueous solutions of polymers P4, P5, DI31, S7, and P6 (polyphosphazene carrying only Jeffamine M1000) at $10^{-1}$ to $10^{-7} \mathrm{mg} \mathrm{mL}^{-1}$, and water (control). The cotyledons were allowed to grow for another 3 days and weighed again. The experiments were performed in triplicate and 10 cotyledons were used for each sample.

\section{Cytotoxicity tests}

The cytotoxicity of the samples against the human breast adenocarcinoma cell line MCF-7 and the non-cancerous primary human lung fibroblast cell line HLF was evaluated using the 2,3-bis(2-methoxy-4-nitro-5-sulfophenyl)-2H-tetrazolium-5carboxanilide assay (XTT) (Cell Proliferation Kit II (XTT), Sigma-Aldrich). Cells were cultured in Dulbecco's modified Eagle's medium (DMEM)-high glucose supplemented with $10 \%$ fetal bovine serum, 1\% penicillin-streptomycin and 1\% L-glutamine. The media and supplements except L-glutamine (PAA Laboratories) were purchased from Sigma-Aldrich. Cells were grown in a humidified $5 \% \mathrm{CO}_{2}$ atmosphere at $37^{\circ} \mathrm{C}$. In all experiments, $70-80 \%$ confluence cells were used. Cells $\left(1 \times 10^{4}\right.$ cells per well $)$ in complete growth medium were seeded into 96-well culture plates. The day after, the medium was changed to serum free medium with P1-P6 aggregate dispersions at different concentrations. The cells were incubated for another 48 hours, the medium was changed to full growth medium and $50 \mu \mathrm{L}$ of XTT reagent was added to each well. Incubation was continued for another 3 hours at $37^{\circ} \mathrm{C}$ in a humidified atmosphere with $5 \% \quad \mathrm{CO}_{2}$ and $100 \%$ humidity. The absorbance was measured at $490 \mathrm{~nm}$ using a GloMax ${ }^{\circledR}$ Multimode Microplate Reader (Promega). Three independent experiments (with each sample in triplicate) were performed, and the cell viability was normalised to the untreated control. The cell viability values were analysed with Origin 2015 (Microcal Origin, OriginLab, MA, USA).

\section{Cell uptake}

Fluorescent dye safranin $\mathrm{O}\left(\lambda_{\text {excitation }}=495 \mathrm{~nm}, \lambda_{\text {emission }}=\right.$ $587 \mathrm{~nm}$ ) was encapsulated in the polyphosphazene aggregates P1-P5 for fluorescence imaging. To this end, $1 \mathrm{mg}$ of polyphosphazenes P1-P5 and $0.1 \mathrm{mg}$ of safranin $\mathrm{O}$ were dissolved in $0.3 \mathrm{~mL}$ of $\mathrm{MeOH}$ and stirred for 1 hour at room temperature in darkness. After that, $1 \mathrm{~mL}$ of deionised water was added and the mixtures were further stirred for another 4 hours at room temperature in darkness. Lyophilisation afforded red coloured solids (safranin-loaded polyphosphazenes SAF-P1, SAF-P2, SAF-P3, SAF-P4 and SAF-P5).

For the cell uptake, cells were grown overnight in 8 well glass bottom $\mu$-Slides. The day after, the medium was changed to a serum free medium (control) or safranin-loaded polyphosphazene aggregate dispersions at $0.1 \mathrm{mg} \mathrm{mL}^{-1}$. The cells were incubated for 6 hours and subsequently counterstained with $1 \mu \mathrm{g} \mathrm{mL}{ }^{-1}$ Hoechst 33342 (Fluka) for 10 minutes. Fluorescence imaging was performed on primary HLF non-cancer cells and MCF-7 cancer cells using an Olympus IX73 inverted microscope with the CY3 channel for the SAF-P1, SAF-P2, SAF-P3, SAF-P4 and SAF-P5 aggregates $\left(\lambda_{\text {excitation }}=550 \mathrm{~nm}, \lambda_{\text {emission }}=565 \mathrm{~nm}\right)$, while the DAPI channel was used for the cell nuclei marker Hoechst $33342\left(\lambda_{\text {excitation }}=345 \mathrm{~nm}, \lambda_{\text {emission }}=455 \mathrm{~nm}\right)$.

\section{Statistics}

Statistical evaluation of data was carried out using Statgraphics Plus 5.1, Professional Edition. Results were assessed using oneway analysis of variance (ANOVA), the Tukey post hoc test for between group comparisons, and multiple comparison and Kruskall-Wallis tests at a 95\% confidence level $(p=0.05)$. Mean values with no significant differences are indicated with the same letter $(p>0.05)$. Significantly different means are marked with the same letter but different numbers following the letter $(p<0.05)$. Mean values with no letter used as a marker stand for significantly different means $(p<0.05)$.

\section{Characterisation}

Characterisation by ATR-FTIR spectroscopy was performed on a PerkinElmer Spectrum 100 FT-IR spectrophotometer using an ATR accessory, with 32 scans and $4 \mathrm{~cm}^{-1}$ resolution from 4000 to $650 \mathrm{~cm}^{-1}$. UV-vis spectra were obtained with a PerkinElmer Lambda $25 \mathrm{UV} / \mathrm{vis}$ spectrophotometer using quartz cuvettes. 
${ }^{1} \mathrm{H},{ }^{13} \mathrm{C}$ and ${ }^{31} \mathrm{P}\left\{{ }^{1} \mathrm{H}\right\}$ NMR spectra were recorded at $298 \mathrm{~K}$ using a Bruker Avance 300 spectrometer operated at $300 \mathrm{MHz}, 75 \mathrm{MHz}$ and $121 \mathrm{MHz}$, respectively. $\mathrm{CDCl}_{3}$ was used as an internal reference for ${ }^{1} \mathrm{H}$ and ${ }^{13} \mathrm{C}$ NMR measurements $\left({ }^{1} \mathrm{H}\right.$ NMR signals were referenced to $\delta=7.26 \mathrm{ppm} ;{ }^{13} \mathrm{C}$ NMR signals were referenced to $77.16 \mathrm{ppm}),{ }^{44}$ while $85 \%$ phosphoric acid was used as an external standard for ${ }^{31} \mathrm{P}\left\{{ }^{1} \mathrm{H}\right\}$ NMR spectra. An Attached Proton Test (APT) ${ }^{13} \mathrm{C}$ NMR experiment was carried out to facilitate carbon assignment by separating carbons according to their number of attached protons $\left(\mathrm{CH}\right.$ and $\mathrm{CH}_{3}$ signals positive, $\mathrm{C}$ and $\mathrm{CH}_{2}$ signals negative) with a single experiment, which is more sensitive than traditional ${ }^{13} \mathrm{C}\left\{{ }^{1} \mathrm{H}\right\}$ NMR. TopSpin 3.5 pl 7 (Bruker BioSpin $\mathrm{GmbH}$ ) software was used for NMR spectra processing. Molecular weights were estimated using a Viscotek GPCmax gel permeation chromatograph (GPC) using a PFG column from PSS (Mainz, Germany) (300 mm $\times 8 \mathrm{~mm}, 5 \mu \mathrm{m}$ particle size), equipped with a Viscotek TDA 305 Triple Detector Array (Malvern, Germany), and calibrated with polystyrene standards from PSS. Samples were eluted with DMF containing

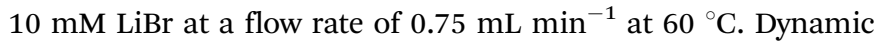
light scattering (DLS) determinations were carried out on a Malvern Zetasizer Nano ZS (Malvern Instruments Ltd, UK) with a detection angle of $173^{\circ}$ and a $4 \mathrm{~mW} \mathrm{He}-\mathrm{Ne}$ laser operated at $633 \mathrm{~nm}$ for backscattering measurements. The samples were prepared at $1 \mathrm{mg} \mathrm{mL}^{-1}$ in deionised water and filtered through a $0.45 \mu \mathrm{m}$ nylon film syringe filter and determinations of hydrodynamic diameters $\left(d_{\mathrm{h}}\right)$ were performed in triplicate using a folded capillary cell DTS1070 at $25{ }^{\circ} \mathrm{C}$. The critical micelle concentrations (CMC) of the P1-P5 samples were determined in deionised water and $\mathrm{PBS}(\mathrm{pH}$ 7.4) via the fluorimetry detection of a pyrene probe added to the samples. ${ }^{45,46}$ P1-P5 samples were prepared at 1.3 to $0.000151 \mathrm{mg} \mathrm{mL}^{-1}$ in water or PBS. $70 \mu \mathrm{L}$ of pyrene dissolved in acetone was added to each sample until a final pyrene concentration of $6 \times 10^{-7} \mathrm{M}$ was achieved. The samples were stirred overnight at room temperature in darkness. The samples were analysed by fluorimetry, with the emission wavelength fixed at $390 \mathrm{~nm}$ and excitation spectra recorded from 330 to $360 \mathrm{~nm} .{ }^{45}$ Calorimetric studies of the samples were conducted on a TA Instrument Q10 differential scanning calorimeter (DSC) using aluminium pans, with a sample weight of approximately $5 \mathrm{mg}$ and a heating rate of $10{ }^{\circ} \mathrm{C} \mathrm{min}{ }^{-1}$ under a nitrogen flow of $20 \mathrm{~mL} \mathrm{~min}{ }^{-1}$. The samples were cooled and heated from $-80{ }^{\circ} \mathrm{C}$ to $400{ }^{\circ} \mathrm{C}$. Atomic Force Microscopy (AFM) images $(10 \mu \mathrm{m} \times 10 \mu \mathrm{m}$ and $2 \mu \mathrm{m} \times$ $2 \mu \mathrm{m}$ ) were taken with an MFP 3D-Stand Alone AFM (Asylum Research) with the cantilever OMCL-AC160TSA of Olympus, at a resonant frequency of $300 \mathrm{kHz}$ and a spring constant of $26 \mathrm{~N} \mathrm{~m}^{-1}$, a $50-70 \%$ set point and a scan rate of $1 \mathrm{~Hz}$. An $80 \mu \mathrm{L}$ droplet of a $1 \mathrm{mg} \mathrm{mL}^{-1}$ aqueous dispersion of the polymers was deposited on a silicon wafer and spin coated at $40 \mathrm{~Hz}$ for $6 \mathrm{~s}$. Transmission Electron Microscopy (TEM) micrographs were recorded with a Jeol JEM-2011 FasTEM (Jeol Ltd, Tokyo, Japan) operated at $100 \mathrm{kV}$. A drop of polymer dispersions in deionised water $\left(1 \mathrm{mg} \mathrm{mL}^{-1}\right)$ was placed on a Pioloform coated 300 Mesh $\mathrm{Cu}$ grid (Plano GmbH, Germany). Excess solution was eliminated with filter paper; the samples were negatively stained with a drop of uranyl acetate aqueous solution at $1 \%$, and dried several hours before measurements.

\section{Results and discussion}

\section{Synthesis and characterisation of polymers P1-P6}

Polyphosphazenes with diosgenin as a model-drug and Jeffamine M1000 were first synthesised with a ratio of initiator to monomer of $1: 25$ and $1: 50$, and a ratio of substituents diosgenin to Jeffamine M1000 of $1: 1$ and 1:2 (Table 1). These preliminary experiments permitted us to assess the efficiency of postpolymerisation functionalisation with steroid molecules (bulky groups) on the poly(dichloro)phosphazene backbone, the effect of the hydrophilicity of the synthesised polyphosphazene (based on the Jeffamine M1000 content) on the aggregation in aqueous dispersions via hydrodynamic parameters and the effect of the steroid content on the size of the dried nanoaggregates using AFM and TEM imaging.

The synthetic approach followed in this work and the structures of the obtained polymers are presented in Fig. 1.

Living cationic polymerisation of trichlorophosphoranimine initiated with triphenylphosphine dichloride in solution $\left(\mathrm{CH}_{2} \mathrm{Cl}_{2}\right)$ at room temperature allowed us to obtain linear poly(dichloro)phosphazenes with a controlled polymerisation degree (20 to 23 for P1, P2, P4, P5, and P6 and 34 for P3) adjusted through the initiator to monomer ratio, and low polydispersities of 1.31-1.50 for the prepared polymers, consistent

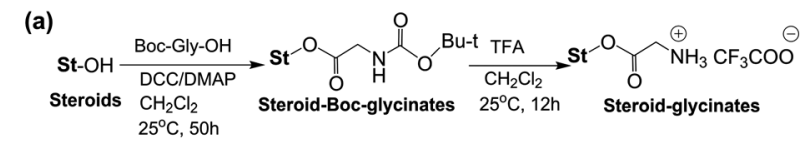

(b)
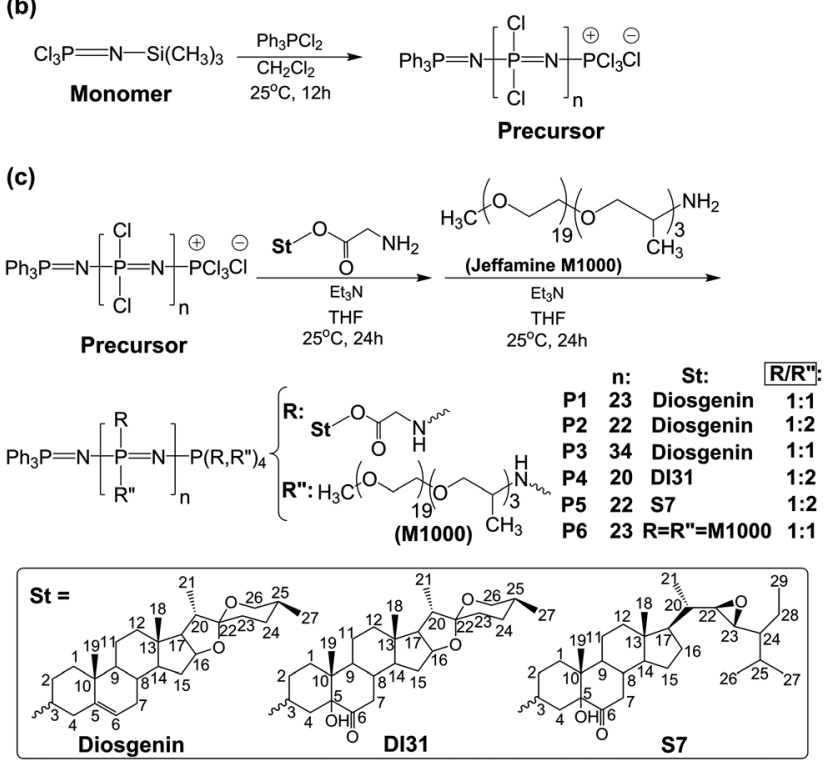

Fig. 1 Scheme of the synthetic route and structures of prepared polyphosphazenes P1-P6. (a) Synthesis of steroid glycinates (steroid-glycine- $\mathrm{NH}_{2}$ ), (b) polymerisation of trichlorophosphoranimine to obtain poly(dichloro)phosphazene, (c) post-polymerisation substitution of chlorine atoms with steroid-glycine- $\mathrm{NH}_{2}$ and Jeffamine M1000. 
with previous reports (Fig. 1b). ${ }^{24,28,38}$ Different steroid-glycine$\mathrm{NH}_{2}$ and Jeffamine M1000 (PEO-PPO-NH$H_{2}$ ) were later introduced via post-polymerisation substitution of the chlorine atoms in poly(dichloro)phosphazene, firstly introducing the bulky steroid groups and later the linear PEO-PPO-NHsubstituent (Fig. 1c). Complete chlorine substitution of the poly(dichloro)phosphazene $\left(\left[\mathrm{NPCl}_{2}\right]_{n}\right)$, required to avoid later uncontrolled polymer degradation and hydrolysis due to highly labile $\mathrm{P}-\mathrm{Cl}$ bonds, ${ }^{38}$ was confirmed using ${ }^{31} \mathrm{P}\left\{{ }^{1} \mathrm{H}\right\}$ NMR spectroscopy. Thus, the ${ }^{31} \mathrm{P}\left\{{ }^{1} \mathrm{H}\right\}$ NMR spectra of polymers P1-P6 only showed broad peaks at 0.5-1.0 ppm, associated with Jeffamine M1000 used as a substituent, ${ }^{24,26,28,33,38}$ while no characteristic peak of the $\mathrm{P}-\mathrm{Cl}$ bond was observed (ESI $\dagger){ }^{26}$ The presence of the hydrophilic Jeffamine M1000 substituent in the synthesised polymers P1-P6 makes them suitable to be dispersed in aqueous solutions, allowing their later application as carriers for controlled release of agrochemicals. The presence of characteristic aromatic protons of the $\left(\mathrm{C}_{6} \boldsymbol{H}_{5}\right)_{3} \mathrm{P}=\mathrm{N}$ - end group allowed the estimation of the attained degree of polymerisation (DP) for polymers P1-P6 using ${ }^{1} \mathrm{H}$ NMR spectroscopy, which was expected to be near to 25 or 50 from the monomer to initiator feed in the mixture reaction. The integration of aromatic protons $\left(\mathrm{C}_{6} \boldsymbol{H}_{5}\right)_{3} \mathrm{P}=\mathrm{N}-$ at $7.60 \mathrm{ppm}$ of P1-P6 was approximately $15 /(20-23)$ or $15 /(34)$ with respect to integration of $-\mathrm{O}-\mathrm{CH}_{2}-\mathrm{CH}_{2}-\mathrm{O}-$ and $\mathrm{CH}_{3} \mathrm{O}-$ protons of Jeffamine $\mathrm{M} 1000$ at 3.62-3.63 and $3.36 \mathrm{ppm}$, respectively. The degree of functionalisation with the two substituents (steroid-glycine- $\mathrm{NH}_{2}$ and Jeffamine M1000) was similarly estimated (ESI $\dagger$ ). ${ }^{28}$ It is observed in Table 1 that the DP of polyphosphazene with diosgenin and Jeffamine M1000 was in good agreement with the initiator to monomer ratio feed composition for the reaction when the polymers were prepared with 25 repeating units (polymers P1, P2, and P6). However, polymer P3 prepared with an initiator to monomer ratio of 1:50 only reached an estimated DP of 34, which is consistent with the results of Wilfert et $a l^{24}$ when conducting phosphine-mediated polymerisations. The polyphosphazenes carrying DI31 or S7 and Jeffamine M1000 (P4 and P5) were synthesised with an initiator to monomer ratio of $1: 25$, allowing us to attain a DP of 20-22. As observed from ${ }^{1} \mathrm{H}$ NMR data (ESI $\dagger$ ), the steroid to Jeffamine M1000 mole ratios in the feed $(1: 2)$ and in the obtained polymers were also in good agreement. The molecular weights of polymers P1-P6 determined by GPC calibrated against linear polystyrene standards deviated by 2-4 orders of magnitude from the expected values calculated for the polymers, as previously reported and ascribed to the different hydrodynamic volume of the branched polyphosphazenes and linear polystyrene standards. ${ }^{28}$ Then, GPC measurements were used in this research as a guide of molecular weights for similarly related polyphosphazenes and to check the polydispersities of prepared polymers P1-P6.

Amphiphilic co-substituted polyphosphazenes might selfassemble or self-aggregate at molecular and supramolecular levels in a micelle-like array with a core formed of hydrophobic moieties and a shield of hydrophilic groups in contact with water molecules, as a result of favoured intramolecular and intermolecular interactions of hydrophobic groups and van der Waals and hydrogen bond interactions of hydrophilic groups and water molecules of the solvent. ${ }^{30,39,47,48}$ Furthermore, the hydrophilic Jeffamine M1000 shell, with a similar structure to poly(ethylene glycol), is expected to prolong the blood circulation time and to protect the lipophilic steroids in the micelle core of P1-P5 polymers in aqueous media for potential antitumoral use. ${ }^{49}$ The average hydrodynamic diameters $\left(d_{\mathrm{h}}\right)$ in water and PBS obtained using dynamic light scattering, and the sizes of dried nanoaggregates from AFM micrographs $\left(d_{\mathrm{AFM}}\right)$ and TEM micrographs $\left(d_{\text {TEM }}\right)$ of polymers P1-P6 are shown in Table 2.

P6 showed an average hydrodynamic diameter corresponding to predominant individual hydrated polymer chains in water (Table 2 and Fig. SI-39 and SI-45 in the ESI $\dagger$ ). It might be due to the composition of P6, formed only for the hydrophilic Jeffamine M1000 bonded to the P-N backbone. P1 and $\mathbf{P 3}$ polymers with the same ratio of hydrophilic to hydrophobic substituents (a diosgenin to Jeffamine M1000 ratio of 1:1) exhibited similar average hydrodynamic diameters ca. 160-170 nm in water and PBS, even when the DP of P3 was 1.4 times the one obtained for P1. Besides, polymer P2, with a higher content of hydrophilic Jeffamine M1000, exhibited an approximately $20 \%$ to $34 \%$ bigger average hydrodynamic diameter when compared to P1 and P3 in water and PBS respectively. However, polymers P4 and P5 with a similar DP and steroid to Jeffamine M1000 ratio to P2 displayed lower average hydrodynamic sizes than P2. It is noteworthy that polymers P1-P6 exhibited a bimodal size distribution by intensity or volume of their hydrodynamic diameters (ESI $\dagger$ ), related to the dynamic formation of aggregates with different sizes in water, probably due to the self-assembly process. Particularly, polymers P2, P4 and P5 showed an unimodal size distribution by volume with sole peaks observed at 9-10 nm, which indicate

Table 2 Hydrodynamic sizes, average AFM and TEM diameters of dried nanoaggregates, and steroid weight contents of polymers P1-P6

\begin{tabular}{|c|c|c|c|c|c|c|c|}
\hline Sample & $d_{\mathrm{h}}{ }^{a} \mathrm{~nm}(\mathrm{PDI})$ & $d_{\mathrm{h}}^{b} \mathrm{~nm}(\mathrm{PDI})$ & $d_{\mathrm{AFM}} \mathrm{nm}$ & $d_{\mathrm{TEM}} \mathrm{nm}$ & $\mathrm{CMC}^{a} \mathrm{mg} \mathrm{mL}{ }^{-1}$ & $\mathrm{CMC}^{b} \mathrm{mg} \mathrm{mL^{-1 }}$ & $\mathrm{Wt} \%$ \\
\hline P1 & $164 \pm 2^{\mathrm{a}}(0.21)$ & $160 \pm 3^{\mathrm{a}}(0.29)$ & $58 \pm 5^{\mathrm{d} 1}$ & $53 \pm 9^{\mathrm{d}}$ & 0.040 & 0.013 & 26.5 \\
\hline P2 & $200 \pm 5(0.34)$ & $216 \pm 1(0.27)^{\mathrm{c}}$ & $88 \pm 3$ & $40 \pm 7^{\mathrm{d} 2}$ & 0.0025 & 0.0030 & 16.2 \\
\hline P3 & $169 \pm 2(0.23)$ & $162 \pm 1^{\mathrm{a}}(0.26)$ & $61 \pm 6^{\mathrm{d} 1}$ & $35 \pm 8^{\mathrm{d} 2}$ & 0.037 & 0.017 & 26.6 \\
\hline $\mathbf{P 4}$ & $122 \pm 1(0.66)$ & $101 \pm 2(0.70)$ & $36 \pm 8^{\mathrm{d} 2}$ & $42 \pm 5^{\mathrm{d} 2}$ & 0.0040 & 0.0043 & 16.3 \\
\hline P5 & $151 \pm 2(0.59)$ & $163 \pm 4^{\mathrm{a}}(0.63)$ & $52 \pm 2^{\mathrm{d} 1}$ & $37 \pm 8^{\mathrm{d} 2}$ & 0.0024 & 0.0035 & 17.6 \\
\hline P6 & $6.0 \pm 0.2^{b}(0.27)^{\mathrm{c}}$ & $6.5 \pm 0.3^{\mathrm{b}}(0.40)$ & - & - & - & - & 0 \\
\hline
\end{tabular}

${ }^{a}$ Average hydrodynamic diameter $\left(d_{\mathrm{h}}\right)$ in water by DLS, critical micelle concentration (CMC) in water. ${ }^{b}$ Average hydrodynamic diameter $\left(d_{\mathrm{h}}\right)$ in PBS by DLS, critical micelle concentration (CMC) in PBS. Diameter of dried nanoaggregates by AFM $\left(d_{\mathrm{AFM}}\right)$. Diameter of dried nanoaggregates by TEM $\left(d_{\text {TEM }}\right)$. Steroid weight contents (wt\%). 
the key contribution of single or a few polymer chains to the self-assembly process of these amphiphilic polyphosphazenes as small aggregates in water. However, further studies are required for a proper understanding of the factors controlling the self-assembly mechanism and the hydrodynamic sizes $\left(d_{\mathrm{h}}\right)$ of polyphosphazenes in water. Nevertheless, polymers P1-P5 formed aggregates in aqueous medium with appropriate sizes (less than $200 \mathrm{~nm}$ ) for possible medical or agrochemical applications. $^{18,50,51}$

The dried aggregates of P1-P5 polymers appeared as aggregates and single rounded particles of approximately 35 to $90 \mathrm{~nm}$ when observed using AFM and TEM (Fig. 2 and Fig. SI-37 and SI-38 in the ESI $\dagger$ ), with significant P1-P5 shrinkage attributed to water removal during drying and collapse of the hydrophilic Jeffamine M1000 shell. ${ }^{49,52}$ The particle sizes determined using AFM followed the same trend of hydrodynamic sizes estimated in water with DLS.

The critical micelle concentrations (CMC) of polymers P1-P5 were determined in water and in PBS according to their intended application as agrochemical and as anticancer drug carriers (Table 2 and Fig. SI-46 in the ESI $\dagger$ ). Interestingly the less hydrophilic polymers P1 and P3 exhibited the highest CMC values in water and PBS. However, all the synthesised polymers showed a good ability to form aqueous aggregates with a micelle-like structure characterised by $\mathrm{CMC}$ values from 0.0024 to $0.04 \mathrm{mg} \mathrm{mL}^{-1}$.

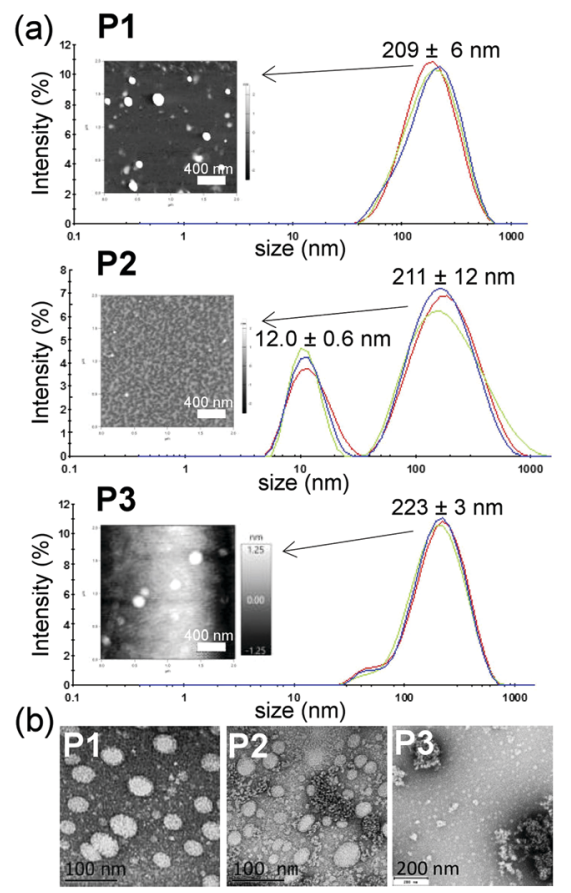

Fig. 2 (a) Hydrodynamic diameter by intensity distribution for polymers P1-P3 in deionised water (concentration $1 \mathrm{mg} \mathrm{mL}^{-1}$ ). Further DLS data can be seen in the ESI† (Fig. SI-37-SI-45). The inserts show AFM micrographs of polymers $\mathbf{P 1}-\mathbf{P 3}$ dispersed in deionised water (concentration $1 \mathrm{mg} \mathrm{mL}^{-1}$ ). (b) TEM micrographs of polymers P1-P3 dispersed in deionised water (concentration $1 \mathrm{mg} \mathrm{mL}^{-1}$ ).

\section{Diosgenin and brassinosteroid release studies}

In this research, the influence of the diosgenin content by weight (wt\%) of polymers P1 (26.5\%) and P3 (26.6\%) compared to $\mathbf{P 2}(16.2 \%)$, the hydrodynamic sizes of the polyphosphazenes $\mathbf{P 1}$ and P3 compared to P2, and the DP of polymers P1 and P2 $(n=25)$ compared to $\mathbf{P 3}(n=50)$ on the release profiles is studied.

All in vitro release experiments were carried out at $\mathrm{pH} 6.0$ and $25{ }^{\circ} \mathrm{C}$ to simulate the slightly acidic environment found inside the vacuoles in vegetal cells, where the particles are stored once having entered the plant cells via endocytosis. ${ }^{53,54}$ It must be noted that hydrolysis of the ester bond in the steroid glycinate moiety and degradation of the polyphosphazene backbone in aqueous medium at neutral $\mathrm{pH}$ and $25{ }^{\circ} \mathrm{C}$ are minimal or very slow, but significant hydrolysis occurs under acidic conditions. ${ }^{25,26}$ However, in vivo vacuolar degradation of substances in plants is mostly enzyme-promoted and the loaded polymers P1-P5 will suffer hydrolysis faster and more extensively due to esterases, phosphatases and other enzymes. ${ }^{55-57}$ Additionally, acid-promoted diosgenin and brassinosteroid release from the P1-P5 aggregates would facilitate drug release and accumulation in acidic cancer tissues rather than in normal cells, for potential antitumour therapeutic applications. ${ }^{58}$ The release experiments were extended up to $106 \mathrm{~h}$ (approximately 4 days), because the intended in vitro activity evaluation of agrochemical bearing polymers $\mathbf{P 4}$ and $\mathbf{P 5}$ will be performed 3 days after application. The in vitro release profiles of diosgenin bearing polymers P1-P3 in PBS (pH 6.0) at $25{ }^{\circ} \mathrm{C}$ are shown in Fig. 3a.

The observed trend of the release rates was $\mathbf{P 2}>\mathbf{P 3} \approx \mathbf{P 1}$, with a cumulative diosgenin release of ca. 33\% (P2) and 21\% (P1 and P3) after 4 days. The release appeared faster and almost linear during the first $8 \mathrm{~h}$, with approximately half of the total diosgenin released with a slope ranging from 1.34 to $2.5 \% \mathrm{~h}^{-1}$, and an adjusted $R$-square of $0.98-0.99$ (Table SI- 1 in the ESI $\dagger$ ). The more hydrophilic and bigger particles of polymer P2, with a lower content of hydrophobic diosgenin, exhibited faster and significantly higher drug release after 4 days than polymers P1 and P3, both with $26.6 \%$ of diosgenin. It was expected that the more hydrophilic polymer P2 with a diosgenin content by weight 40\% lower than in P1 and P3 and with the capability to form particles with $34 \%$ bigger hydrodynamic diameters in PBS will occur with less compact and less dense hydrophobic cores (Fig. 3c), which are more suitable for ester hydrolysis and diosgenin release. On the other hand, polymers P1 and P3 with the same diosgenin content and quite similar hydrodynamic diameters of particles in aqueous medium showed similar release profiles and no significant difference of the total diosgenin released after $106 \mathrm{~h}$ at a 95\% confidence level (approximately 21\% of diosgenin contained within P1 and P3 was released).

The agrochemical content by weight (wt\%) of polymers $\mathbf{P 4}$ and P5 was found to be $16.3 \mathrm{wt} \%$ of DI31 (P4) and $17.6 \mathrm{wt} \%$ of S7 (P5) respectively, as estimated using ${ }^{1} \mathrm{H}$ NMR data (ESI $\dagger$ ). The release profile of S7 bearing polymer $\mathbf{P 5}$ is characterised by an initial burst release up to $15.5 \%$ in the first $2 \mathrm{~h}$ (Fig. $3 \mathrm{~b}$ ). It was observed a fast $\mathrm{S} 7$ release rate during the first $8 \mathrm{~h}$ deviated 

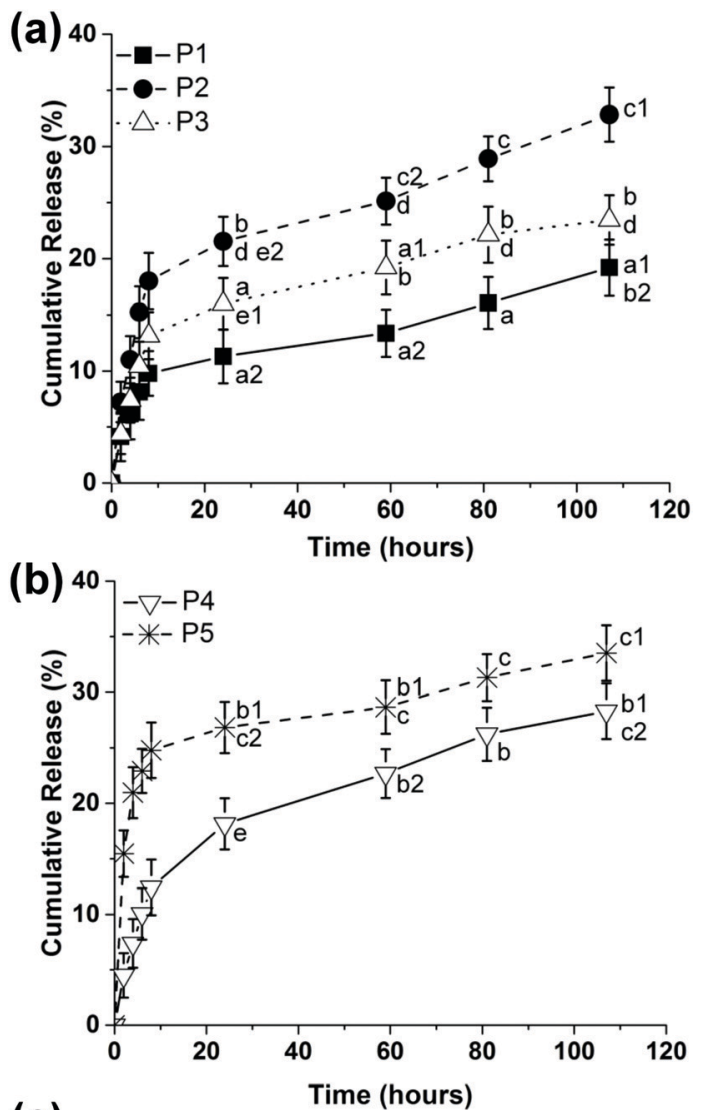

(c)

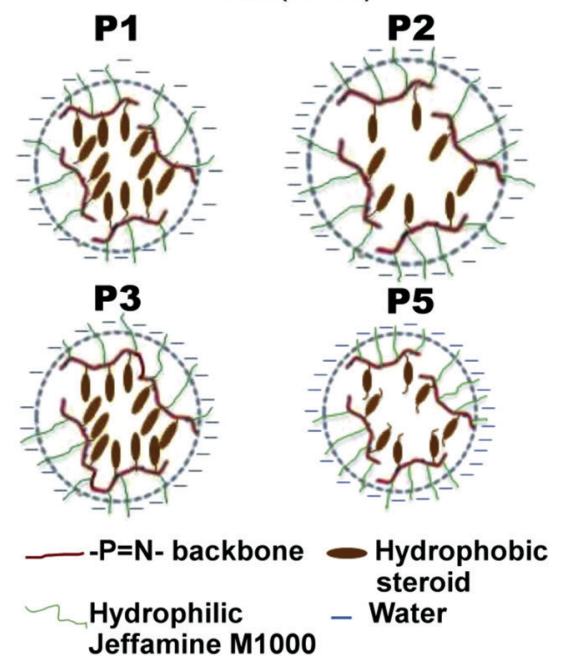

Fig. 3 (a) Cumulative diosgenin release from polymers $\mathbf{P} 1$ to $\mathbf{P} 3$ at $25^{\circ} \mathrm{C}$ in PBS at pH 6.0; (b) cumulative steroid release from polymers $\mathbf{P 4}$ and $\mathrm{P} 5$ at $25^{\circ} \mathrm{C}$ in PBS at pH 6.0. The amounts of diosgenin and steroids DI31 and S7 released were estimated using a calibration curve for the free drugs in PBS at $\mathrm{pH}$ 6.0. (c) Cross-section scheme of the proposed structure of polyphosphazene nanoaggregates P1-P3 and P5 in aqueous medium.

of linear behaviour (adjusted $R$-square 0.9132 , Table SI- 1 in the ESI $\dagger$ ), followed by a slower release rate from $24 \mathrm{~h}$ to $106 \mathrm{~h}$ (Fig. 3b). The initial burst release of S7 from polymer P5 might be due to the mobility of the lateral chain (carbons C20 to C29) in $\mathrm{S} 7$ combined with the superior hydrophilicity of polymers $\mathbf{P 4}$ and P5, which aids $\mathrm{H}_{3} \mathrm{O}^{+}$and water uptake (required for generation of highly active acylium ions and further reaction with water during ester hydrolysis $)^{59}$ in the less hydrophobic core of P5 aggregates (Fig. 3c). ${ }^{45,60}$ However, there is no significant difference of the total agrochemicals released after $106 \mathrm{~h}$ for polymers P4 and P5 (approximately 31\% of DI31 or S7 contained within polymers $\mathbf{P 4}$ and $\mathbf{P 5}$ was released). It is hypothesised that hydrolysis of the ester bond between the steroids and the glycinate linker attaching the steroids to the polyphosphazene backbone determines the steroid release rates for polymers P1-P5, because drug release of steroid-grafted celluloses and chitosans was also extended over 3-4 days when carried out in similar conditions. ${ }^{15,48}$ On the other hand, the glycine-Jeffamine M1000 bearing polyphosphazene is known to degrade slower, with approximately $10 \%$ of the polymer degraded after 5 days in acetate buffer (pH 5.0) at $37^{\circ} \mathrm{C}^{26}$

\section{In vitro agrochemical activity}

Brassinosteroids and auxin synergistically control vegetal cell division and elongation among other functions at the microscopic level, which is observed macroscopically as plant growth and accretion of biomass. ${ }^{61}$ The crosstalk between the brassinosteroid and auxin signaling pathways is exhaustively studied, with the BRI1 kinase brassinosteroid receptor overexpressed by auxin and brassinazole resistant 1 (BZR1) transcription factor of brassinosteroids capable of regulating auxin-controlled genes. ${ }^{61}$ It is accepted that the brassinosteroid and auxin pathways are highly interconnected, sharing transcriptional targets and controlling gene expression in plants. ${ }^{61}$ The radish cotyledon test, the radish hypocotyl elongation test, and the bending of the lamina joint of rice test are based on detection of brassinosteroid and auxin activities. ${ }^{61}$ These bioassays are frequently used to evaluate the agrochemical activity of different compounds as plant growth regulators. ${ }^{61}$ Recent advances in computer simulation of the BRI1 brassinosteroid receptor 3D structure and molecular docking studies of brassinosteroid-BRI1 interactions allow in silico screening of potential brassinosteroid mimetics. ${ }^{62}$ However, the traditional radish- and rice-based bioassays are still used to properly evaluate the plant growth activity and proper dosage of possible agrochemical candidates. Particularly, the proper concentration of brassinosteroids exogenously applied and the plant developmental stage for brassinosteroid application must be determined to obtain optimal yields. ${ }^{8,9}$

The results as plant growth enhancers of DI31 bearing polymer P4 and S7 bearing polymer P5 against radish (Raphanus sativus) plants are shown in Fig. 4.

The methodology employed to evaluate the agrochemical activity of the studied compounds is based on detection of auxin type activity, ${ }^{43,61}$ expressed as the increased weight of radish cotyledons (Fig. 4a). The same agrochemical activity was observed for both polymers $\mathbf{P 4}$ and $\mathbf{P 5}$ when applied at the same concentrations, except at $10^{-3}$ and $10^{-6} \mathrm{mg} \mathrm{mL}^{-1}$ with $\mathbf{P 4}$ (DI31) being significantly more effective as a plant growth stimulator than P5 (S7) at these two concentrations (Fig. 4b). The stimulatory effect of polymers $\mathbf{P 4}$ and $\mathbf{P 5}$ was maximal at $10^{-1}$ and $10^{-2} \mathrm{mg} \mathrm{mL}{ }^{-1}$ concentrations, with a three times increased radish cotyledon weight as compared to radish cotyledons 

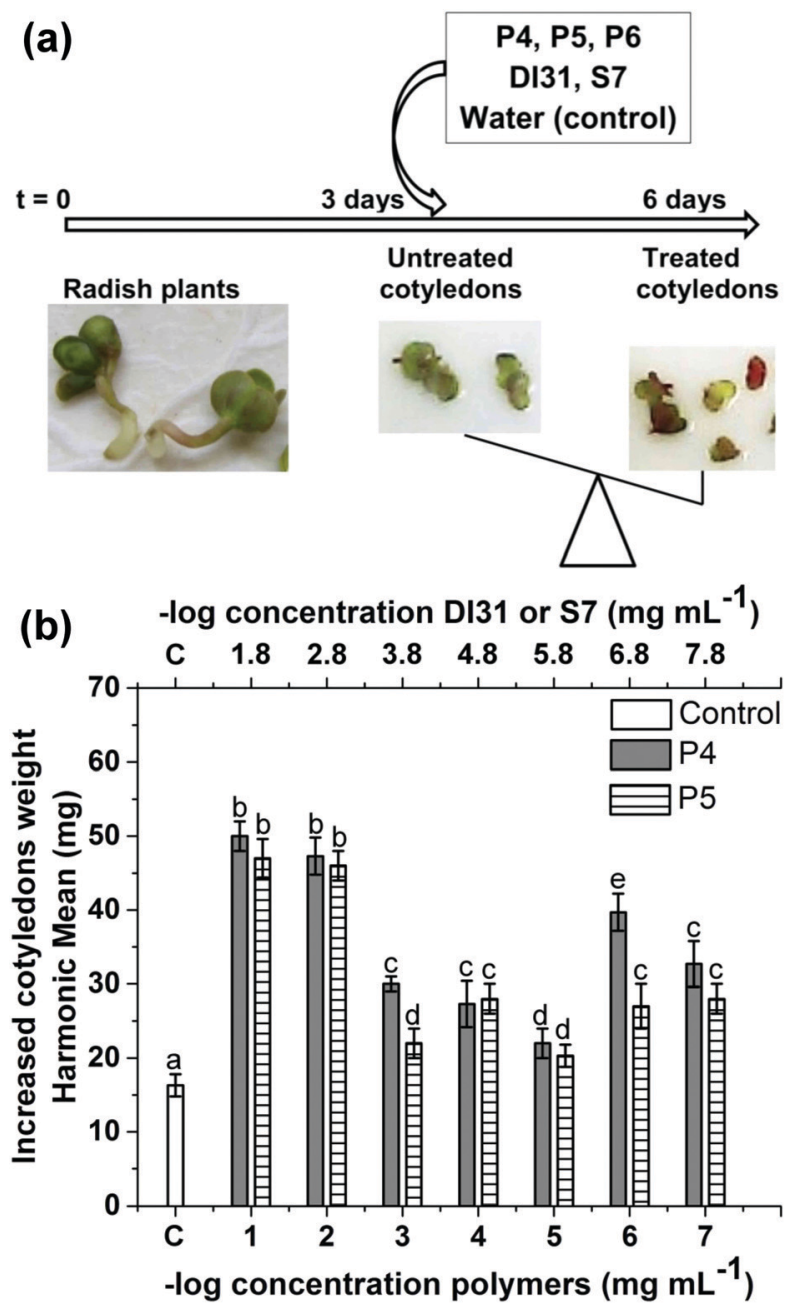

Fig. 4 (a) Scheme of the process to evaluate the agrochemical activity of polymers P4 (DI31), P5 (S7), P6 (Jeffamine M1000), DI31 and S7 using radish cotyledons obtained from radish plants. (b) In vitro agrochemical activity expressed in terms of the increased weight of 10 radish cotyledons as a function of the concentration of applied polymers P4 (DI31) and P5 (S7) (bottom axis) and of the concentration of DI31 and S7 carried on the applied polymers P4 (DI31) and P5 (S7) (top axis), C refers to the control (radish cotyledons treated with water). See the graph showing the agrochemical activity of parent DI31 and S7 and Jeffamine M1000 bearing polymer P6 in the ESI $†$ (Fig. SI-53).

treated with water (control) (Fig. 4b). Further dilutions of $\mathbf{P 4}$ and P5 until $10^{-3}$ to $10^{-7} \mathrm{mg} \mathrm{mL}^{-1}$ concentrations of the polymers still resulted in similar and good agrochemical activity, with almost twice the radish cotyledon weight increase as compared to the control experiment (Fig. 4b). Particularly attractive for further in vivo agrochemical application of polymers P4 and P5 is the slightly superior plant growth enhancer effect observed at the lowest polymer concentrations of $10^{-6}$ and $10^{-7} \mathrm{mg} \mathrm{mL}^{-1}$ (content $10^{-6.8}$ and $10^{-7.8} \mathrm{mg} \mathrm{mL}^{-1}$ of DI31 and S7) as compared to the agrochemical effect of parent DI31 and S7 evaluated at $10^{-7} \mathrm{mg} \mathrm{mL}^{-1}$ (Fig. $4 \mathrm{~b}$ and Fig. SI-53 in the ESI $\dagger$ ). In the same way, polymers $\mathbf{P 4}$ and $\mathbf{P 5}$ displayed higher agrochemical activity at all concentrations as compared to DI31 and S7 tested at the same brassinosteroid concentration, except when P4 and P5 were applied at $10^{-3} \mathrm{mg} \mathrm{mL} \mathrm{m}^{-1}$ (content $10^{-3.8} \mathrm{mg} \mathrm{mL} \mathrm{m}^{-1}$ of DI31 and S7) (Fig. 4b and Fig. SI-53 in the ESI $\dagger$ ).

The agrochemical activity of parent DI31 and S7 (Fig. SI-53 in the ESI $\dagger$ ) showed no significant difference of the plant growth enhancer effect for both the DI31 and S7 agrochemicals when evaluated at equal concentrations. The agrochemical activity of parent DI31 and S7 was diminished with dilutions, but DI31 and S7 still exhibited significant stimulatory activity when applied at $10^{-6}$ and $10^{-7} \mathrm{mg} \mathrm{mL}^{-1}$ (nanomolar concentrations of synthetic analogues of brassinosteroids and natural brassinosteroids are applied as agrochemicals in crops). ${ }^{63,64}$ On the other hand, no stimulatory effect was observed for the Jeffamine M1000 bearing polymer $\mathbf{P 6}$ at all concentrations. Therefore, the beneficial effects of DI31 bearing polymer P4 and S7 bearing polymer P5 observed on radish plants might be due to the sustained release of the incorporated agrochemicals DI31 and S7.

\section{Cytotoxic activity}

Diosgenin is known to exert antiproliferative and cytotoxic effects via activation of p53 proapoptotic protein and caspase-3 on MCF-7 breast cancer cells, as well as to promote the generation of reactive oxygen species that induce cell apoptosis via oxidative stress. ${ }^{19}$ Furthermore, diosgenin is capable of inhibiting the STAT3 signalling pathway in human hepatocellular carcinoma cells, which induces apoptosis and cell cycle arrest in the G1 phase via caspase-3 activation and PARP cleavage. ${ }^{19}$ Diosgenin also downregulates the NF- $\kappa \mathrm{B}$ transcriptional activity, matrix metalloproteinase MMP-2 and MMP-9, Janus kinase JNK, protein kinase B AKT and other factors of several cancer cells. ${ }^{65}$ Interestingly, anti-metastatic activity of diosgenin is reported against the human breast cancer cell line MDA-MB-231 and the human prostate cancer cell line PC-3 through suppression of Vav2 protein and VEGF angiogenic factors. ${ }^{19}$

On the other hand, studies of brassinolide and epibrassinolide natural brassinosteroids on human breast cancer cells and drug resistant small-cell lung carcinoma cells have shown potent anticancer activity and no cytotoxicity to non-cancer BEAS-2 lung epithelial cells. $^{23}$ It is proposed that brassinolide acts on the Wnt signaling pathway of small-cell lung carcinoma cells via a reduction of $\beta$-catenin-dependent genes related to cell division, protection against apoptosis and metastasis. ${ }^{23}$ Similarly to that observed in diosgenin, the anticancer mechanism of action of brassinosteroids is dependent on the generation of reactive oxygen species, inhibition of angiogenic factors, and regulation of the cancer cell cycle and different cancer cell pathways. ${ }^{22}$ These facts and the cell-type and dose-dependent antitumour activity of these compounds motivated us to study the cytotoxic activity, and MCF-7 and primary HLF cell uptake of the diosgenin and brassinosteroid bearing polymers synthesised (P1-P5).

The relative cell viabilities of MCF-7 and primary HLF cells treated with the P1-P5 polymers are shown in Fig. 5 and Fig. SI-54-SI-57 in the ESI. $\dagger$

The Jeffamine M1000 bearing polymer P6 appeared non toxic to MCF7 and HLF cells at $0.1 \mathrm{mg} \mathrm{mL}^{-1}$, with relative cell viabilities of $(97 \pm 4) \%$ and $(94 \pm 6) \%$, respectively (data not shown). The diosgenin bearing polymers P1-P3 showed 
(a)

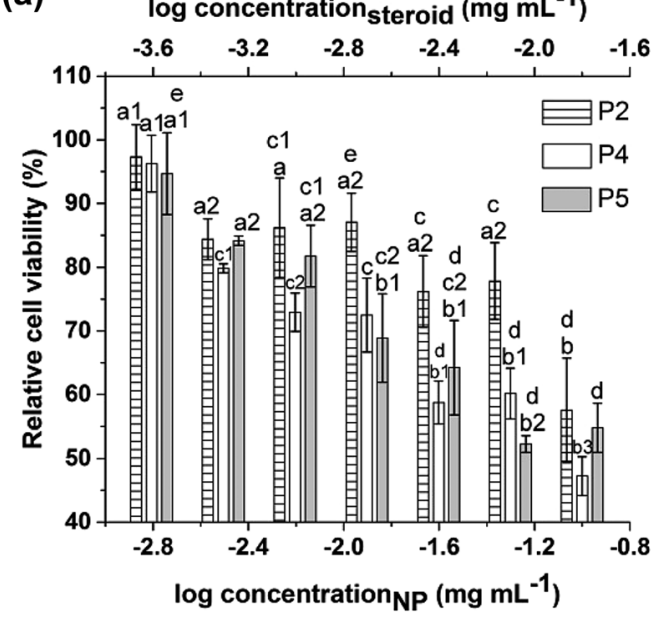

(b)

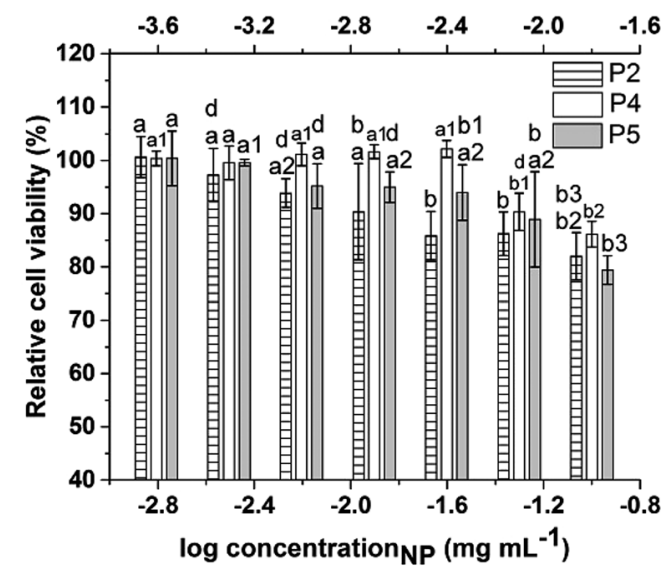

Fig. 5 Relative cell viability of (a) MCF-7 breast cancer cells and (b) noncancer HLF cells treated with polymers P2, P4, and P5. Further relative cell viability data of MCF-7 and HLF cells treated with polymers P1, and P3, and parent steroids diosgenin, DI31 and S7 can be seen in the ESI† (Fig. SI-54-SI-57).

moderate to slight anticancer effects (relative cell viabilities of 60-80\%) when evaluated on MCF-7 at 0.1 to $0.025 \mathrm{mg} \mathrm{mL}^{-1}$ (a diosgenin content of 0.0266 to $0.00665 \mathrm{mg} \mathrm{mL}^{-1}$ for P1 and P3, and 0.0162 to $0.00405 \mathrm{mg} \mathrm{mL}^{-1}$ for P2) (Fig. 5a and Fig. SI-54 in the ESI $\dagger$ ), which were similar to the cytotoxic effect observed for parent diosgenin when evaluated on MCF-7 at 0.005 to $0.000625 \mathrm{mg} \mathrm{mL}^{-1}$ (Fig. SI-56 in the ESI $\dagger$ ). These polymers exhibited almost no toxicity on non-cancer HLF cells at 0.1 to $0.0015625 \mathrm{mg} \mathrm{mL}{ }^{-1}$, with observed relative cell viabilities of approximately $85-100 \%$ (Fig. $5 \mathrm{~b}$ and Fig. SI-55 in the ESI $\dagger$ ), and were similarly non-cytotoxic compared to parent diosgenin at 0.01 to $0.00015625 \mathrm{mg} \mathrm{mL}^{-1}$ (a relative cell viability of $90-100 \%$ ) (Fig. SI-57 in the ESI $\dagger$ ). Interestingly, DI31 bearing polymer $\mathbf{P 4}$ and S7 bearing polymer $\mathbf{P 5}$ exhibited strong to moderate toxicity to MCF-7 cancer cells at 0.1 to $0.00625 \mathrm{mg} \mathrm{mL}^{-1}$ (a DI31 and S7 content of approximately 0.017 to $0.0010625 \mathrm{mg} \mathrm{mL}^{-1}$ ), with observed relative cell viabilities of $50-70 \%$ (Fig. 5a). However, polymers $\mathbf{P 4}$ and $\mathbf{P 5}$ appeared non toxic to HLF cells at all concentrations, with relative cell viabilities of approximately 90-100\% (Fig. 5b). Polymers P4 and P5 with an average hydrodynamic diameter of $101 \mathrm{~nm}$ and $163 \mathrm{~nm}$ respectively, might show extended circulation time and slow renal clearance, with accumulation in cancer tissues due to passive diffusion and an enhanced permeability and retention (EPR) effect. ${ }^{66,67}$ Then, polymers $\mathbf{P 4}$ and $\mathbf{P 5}$ seem to be potential candidates as anticancer drugs. On the other hand, polymers P4 and P5 with no toxicity observed at 0.1 to $0.00156 \mathrm{mg} \mathrm{mL}^{-1}$ to primary HLF cells are safe to be used as agrochemicals at concentrations below $0.1 \mathrm{mg} \mathrm{mL}^{-1}$, or particularly below $10^{-3} \mathrm{mg} \mathrm{mL}^{-1}$ for delivery of recommended $10^{-4}$ to $10^{-7} \mathrm{mg} \mathrm{mL}^{-1}$ of DI31 or S7 to crops. ${ }^{11,13,63,64}$

\section{Cell uptake}

The uptake of safranin-loaded P1-P5 aggregates in non-cancer primary HLF cells and MCF-7 cancer cells was assessed using fluorescence microscopy. Samples SAF-P1, SAF-P2, SAF-P3, SAF-P4 and SAF-P5 (Fig. 6 and Fig. SI-58-SI-65 in the ESI $\dagger$ ) internalized well in both cell lines after 6 hours (safranin O related red fluorescence), and cell nuclei were counterstained with Hoechst 33342 (associated blue fluorescence). The safraninloaded polyphosphazene aggregates seem to be distributed mostly in the cytoplasm after internalization into cells. Stronger red fluorescence of safranin is observed in the cytoplasm, whereas weaker red fluorescence due to slow diffusion of safranin from the safranin-loaded polymeric aggregates to the cell nuclei is visible for both non-cancer HLF and MCF-7 cancer cells (Fig. 6 and Fig. SI-58-SI-65 in the ESI $\dagger$ ). ${ }^{49,58}$

The experimental results discussed herein demonstrate that it is possible to tune the steroid release rate of polyphosphazene-based polymers with diosgenin and Jeffamine M1000 as co-substituents (P1-P3), as a function of the hydrodynamic size and hydrophilicity of the synthesised polymers. Later post-polymerisation functionalisation together with the right selection of substituents allows obtaining polymers with different hydrophilicities that

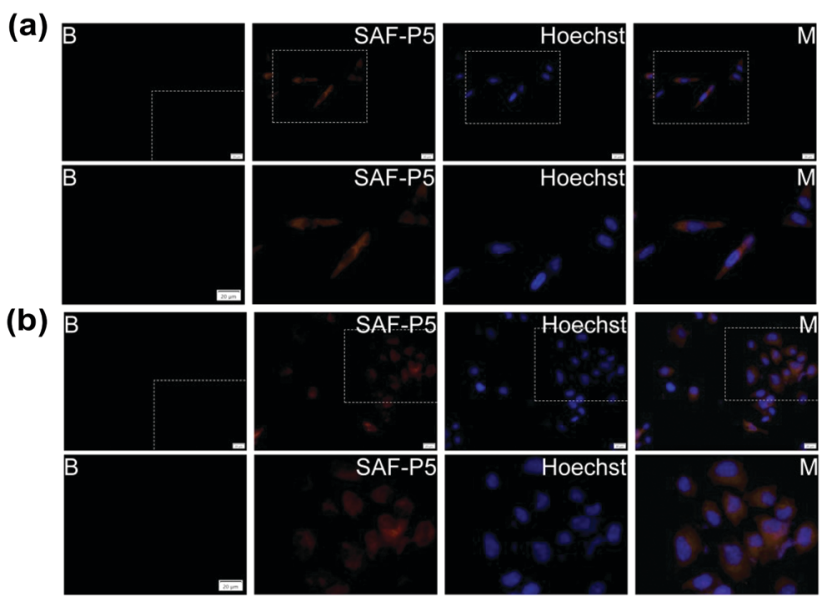

Fig. 6 HLF and MCF-7 cell fluorescence images and slices of cells without particles and Hoechst (B). (a) Primary HLF cells with $0.1 \mathrm{mg} \mathrm{mL}^{-1}$ SAF-P5 aggregates, $1 \mu \mathrm{g} \mathrm{mL}^{-1}$ of Hoechst 33342 and merged pictures (M); (b) MCF-7 cells with $0.1 \mathrm{mg} \mathrm{mL}^{-1}$ of SAF-P5 aggregates, $1 \mu \mathrm{g} \mathrm{mL}^{-1}$ of Hoechst 33342 and merged pictures (M), scale bars represent $20 \mu \mathrm{m}$. 
result in aqueous aggregates ranging from nanoaggregates to microaggregates. ${ }^{28,29,31}$ The controlled and partial release of covalently linked DI31 from polymer P4 and S7 from polymer P5 caused very good in vitro agrochemical activity. Then, it is expected that polyphosphazenes P4 and P5 will exert an excellent and extended plant growth stimulator effect on crops using lower quantities than typical exogenous applications of DI31 and S7 when used as agrochemicals. ${ }^{68,69}$ Additional benefits of polymers like P4 and P5 are the lower environmental impact associated with their use in agriculture, as they do not need incorporation of harmful additives to ensure colloidal stability and proper dispersion in water as the commercial formulations of DI31, 24-epibrassinolide and other brassinosteroids on the market. ${ }^{68,70}$ On the other hand, diosgenin bearing polymers P1-P3 exhibited moderate cytotoxicity to MCF-7 and no toxicity to primary HLF cells at medium to high concentrations. DI31 bearing polymer P4 and S7 bearing polymer $\mathbf{P 5}$ showed strong to moderate cytotoxicity to MCF-7 and no toxicity to primary HLF cells at almost all concentrations tested. Direct injection of $\mathbf{P 4}$ and $\mathbf{P 5}$ particles in solid tumours and/or their selective accumulation in cancer tissues via the EPR effect and passive diffusion might enhance the therapeutic effect with a reduction of side effects. ${ }^{66,67,71}$ Besides, polymers P4 and P5 are safe to be used in agriculture at concentrations below $10^{-3} \mathrm{mg} \mathrm{mL}^{-1}$. Additionally, degradation of the polyphosphazene backbones to ammonia and phosphates in aqueous medium, ${ }^{38}$ broad research about various polyphosphazenes in nanomedicine based on their biocompatibility, ${ }^{72,73}$ and no cytotoxic and inhibitory agrochemical effect observed for polymer P6 put forward a potential application of polymers P4 and P5 for chemotherapy treatments and in agriculture.

\section{Conclusions}

Six different polyphosphazene-based nanocarriers were prepared for sustained release of diosgenin and the agrochemicals DI31 and S7, via controlled living cationic polymerisation and later post-polymerisation functionalisation with the steroids and hydrophilic Jeffamine M1000, an amine capped polyetheramine copolymer. Polyphosphazenes P1-P3 showed moderate toxicity to cancer MCF-7 and no toxicity to non-cancer HLF cells when evaluated at medium to high concentration. Polyphosphazenes P4 and P5 carrying approximately 17 wt\% of DI31 (P4) and S7 (P5) respectively, formed aqueous nanoaggregates that exerted an excellent stimulant plant growth effect on radish cotyledons due to the controlled delivery of the agrochemicals. Cytotoxic evaluation of polymers P4 and P5 showed that both polyphosphazenes were toxic to MCF-7 at concentrations above $0.003125 \mathrm{mg} \mathrm{mL}^{-1}$ and harmless to HLF cells at concentrations below $0.1 \mathrm{mg} \mathrm{mL}{ }^{-1}$. MCF-7 and HLF cells showed good cell uptake of all synthesised steroid bearing polymers (P1-P5) after 6 hours. Therefore, the $\mathbf{P 4}$ and $\mathbf{P 5}$ polymers applied at $10^{-4}$ to $10^{-6} \mathrm{mg} \mathrm{mL}^{-1}$ for delivery of the recommended DI31 or S7 quantities to plants should be harmless to humans. The results attained suggest that preparation of polyphosphazenes with attached brassinosteroids (i.e. P4 and P5) is a promising strategy for the synthesis of more efficient agrochemicals with reduced environmental impact, and of promising brassinosteroid-based antitumour candidates. However, exhaustive in vivo evaluation of these potential anticancer polyphosphazenes must be performed before their clinical use as antitumoral agents.

\section{Conflicts of interest}

There are no conflicts to declare.

\section{Acknowledgements}

Erasmus Mundus is acknowledged for a scholarship to JPQ. The authors would like to acknowledge Prof. Ian Teasdale for his valuable comments on the manuscript. The authors thank Günter Hesser for training with TEM imaging of nanoparticles and Lisa M. Uiberlacker for AFM imaging of nanoparticles at JKU Linz, Austria. The access to NMR facilities of Upper Austrian - South Bohemian Research Infrastructure Center in JKU Linz, Linz, Austria, supported by the European Union (ETC Austria-Czech Republic 2007-2013, Project M00146) is also acknowledged.

\section{Notes and references}

1 J. Oklestova, L. Rárová, M. Kvasnica and M. Strnad, Phytochem. Rev., 2015, 14, 1053-1072.

2 A. Banerjee and A. Roychoudhury, J. Plant Growth Regul., 2018, 37, 1025-1032.

3 H. Siddiqui, S. Hayat and A. Bajguz, Acta Physiol. Plant., 2018, 40, 59.

4 A. Anwar, Y. Liu, R. Dong, L. Bai, X. Yu and Y. Li, Biol. Res., 2018, 51, 46.

5 B. Shahzad, M. Tanveer, Z. Che, A. Rehman, S. A. Cheema, A. Sharma, H. Song, S. Rehman and D. Zhaorong, Ecotoxicol. Environ. Saf., 2018, 147, 935-944.

6 M. K. Kanwar, A. Bajguz, J. Zhou and R. Bhardwaj, J. Plant Growth Regul., 2017, 36, 1002-1030.

7 T. Yokota, T. Ohnishi, K. Shibata, M. Asahina, T. Nomura, T. Fujita, K. Ishizaki and T. Kohchi, Phytochemistry, 2017, 136, 46-55.

8 U. K. Divi and P. Krishna, New Biotechnol., 2009, 26, 131-136.

9 D. Hola, O. Rothova, M. Kocova, L. Kohout and M. Kvasnica, Plant Growth Regul., 2010, 61, 29-43.

10 Y. C. Serrano, R. R. Fernandez, F. R. Pineda, L. T. S. Pelegrin, D. G. Fernandez and M. C. G. Cepero, Am. J. Biosci. Bioeng., 2015, 3, 197-202.

11 E. Terry, M. M. Diaz de Armas, J. Ruiz, T. Tejeda, M. E. Zea and F. Camacho-Ferre, J. Food, Agric. Environ., 2012, 10, 386-389.

12 M. M. de Assis-Gomes, D. T. Pinheiro, R. Bressan-Smith and E. Campostrini, Theor. Exp. Plant Physiol., 2018, 30, 193-201.

13 M. Serna, F. Hernández, F. Coll and A. Amorós, Sci. Hortic., 2012, 143, 29-37. 
14 E. V. R. Campos, J. L. de Oliveira, C. M. G. da Silva, M. Pascoli, T. Pasquoto, R. Lima, P. C. Abhilash and L. F. Fraceto, Sci. Rep., 2015, 5, 13809.

15 J. P. Quiñones, C. C. Mardare, A. W. Hassel and O. Brüggemann, Eur. Polym. J., 2017, 93, 706-716.

16 M. Kah, R. S. Kookana, A. Gogos and T. D. Bucheli, Nat. Nanotechnol., 2018, 13, 677-684.

17 A. Pérez-de-Luque, Front Environ. Sci., 2017, 5, 12.

18 P. Wang, E. Lombi, F.-J. Zhao and P. M. Kopittke, Trends Plant Sci., 2016, 21, 699-712.

19 M. Jesus, A. P. J. Martins, E. Gallardo and S. Silvestre, J. Anal. Methods Chem., 2016, 4156293.

20 I. Herráiz, Chemical Pathways of Corticosteroids, Industrial Synthesis from Sapogenins. In Microbial Steroids: Methods and Protocols, Methods in Molecular Biology, ed. J.-L. Barredo and I. Herráiz, Springer Science+Business Media LLC, 2017, vol. 1645, pp. 15-27.

21 M. Okawara, F. Hashimoto, H. Todo, K. Sugibayashi and Y. Tokudome, Int. J. Pharm., 2014, 472, 257-261.

22 O. V. Panibrat, V. N. Zhabinski and V. A. Khripach, Anticancer Potential of Brassinosteroids. In Brassinosteroids: Plant Growth and Development, ed. S. Hayat, M. Yusuf, R. Bhardwaj and A. Bajguz, Springer, Singapore, 2019, pp. 389-406.

23 D. Sadava and S. E. Kane, Biochem. Biophys. Res. Commun., 2017, 493, 783-787.

24 S. Wilfert, H. Henke, W. Schoefberger, O. Brüggemann and I. Teasdale, Macromol. Rapid Commun., 2014, 35, 1135-1141.

25 H. Henke, O. Brüggemann and I. Teasdale, Macromol. Rapid Commun., 2017, 38, 1600644.

26 S. Wilfert, A. Iturmendi, W. Schoefberger, K. Kryeziu, P. Heffeter, W. Berger, O. Brüggemann and I. Teasdale, J. Polym. Sci., Part A: Polym. Chem., 2014, 52, 287-294.

27 A. Iturmendi, U. Monkowius and I. Teasdale, ACS Macro Lett., 2017, 6, 150-154.

28 I. Teasdale, S. Wilfert, I. Nischang and O. Brüggemann, Polym. Chem., 2011, 2, 828-834.

29 Z. Tian, Y. Zhang, X. Liu, C. Chen, M. J. Guiltinan and H. R. Allcock, Polym. Chem., 2013, 4, 1826-1835.

30 A. Linhardt, M. König, W. Schofberger, O. Brüggemann, A. K. Andrianov and I. Teasdale, Polymers, 2016, 8, 161.

31 N. L. Morozowich, J. L. Nichol, R. J. Mondschein and H. R. Allcock, Polym. Chem., 2012, 3, 778-786.

32 S. Rothemund, T. B. Aigner, A. Iturmendi, M. Rigau, B. Husár, F. Hildner, E. Oberbauer, M. Prambauer, G. Olawale, R. Forstner, R. Liska, K. R. Schröder, O. Brüggemann and I. Teasdale, Macromol. Biosci., 2015, 15, 351-363.

33 H. Henke, K. Kryeziu, J. Banfic, S. Theiner, W. Körner, O. Brüggemann, W. Berger, B. K. Keppler, P. Heffeter and I. Teasdale, Macromol. Biosci., 2016, 16, 1239-1249.

34 C. M. Hackl, B. Schoenhacker-Alte, M. H. M. Klose, H. Henke, M. S. Legina, M. A. Jakupec, W. Berger, B. K. Keppler, O. Brüggemann, I. Teasdale, P. Heffeter and W. Kandioller, Dalton Trans., 2017, 46, 12114-12124.

35 Z. Huang, Y. Pan, J. Guo, Y. Chao, W. Shen, C. Wang and H. Xu, RSC Adv., 2016, 6, 48694-48698.
36 T. Mayer-Gall, D. Knittel, J. S. Gutmann and K. Opwis, ACS Appl. Mater. Interfaces, 2015, 7, 9349-9363.

37 M. Rezakazemi, M. Sadrzadeh and T. Matsuura, Prog. Energy Combust. Sci., 2018, 66, 1-41.

38 S. Rothemund and I. Teasdale, Chem. Soc. Rev., 2016, 45, 5200-5215.

39 J. X. Zhang, L. Y. Jin and K. J. Zhu, J. Biomed. Mater. Res., Part A, 2006, 76A, 773-780.

40 L.-X. Sun, W.-W. Fu, W. Li, K.-S. Bi and M.-W. Wang, Z. Naturforsch., 2006, 61c, 171-176.

41 B. Wang, E. Rivard and I. Manners, Inorg. Chem., 2002, 41, 1690-1691.

42 H. A. Deshpande and S. R. Bhalsing, Physiol. Mol. Biol. Plants, 2014, 20, 89-94.

43 E. Alonso-Becerra, Y. Bernardo-Otero, F. Coll-Manchado, F. Guerra-Martínez, G. Martínez-Massanet and C. PérezMartínez, J. Chem. Res., 2007, 5, 268-271.

44 H. E. Gotlieb, V. Kotlyar and A. Nudelman, J. Org. Chem., 1997, 62, 7512-7515.

45 F. Cheng, T. Su, K. Luo, Y. Pu and B. He, J. Mater. Chem. B, 2019, 7, 1005-1016.

46 M. Ashjari, S. Khoee, A. R. Mahdavian and R. Rahmatolahzadeh, J. Mater. Sci.: Mater. Med., 2012, 23, 943-953.

47 J.-M. Lehn, Angew. Chem., Int. Ed. Engl., 1990, 29, 1304-1319. 48 J. P. Quiñones, H. Peniche and C. Peniche, Polymers, 2018, 10, 235.

49 L. Xu, Y. Yang, M. Zhao, W. Gao, H. Zhang, S. Li, B. He and Y. Pu, J. Mater. Chem. B, 2018, 6, 1076-1084.

50 C. M. Beddoes, C. P. Case and W. H. Briscoe, Adv. Colloid Interface Sci., 2015, 218, 48-68.

51 C. Ma, X. Zhang, C. Du, B. Zhao, C. He, C. Li and R. Qiao, Bioconjugate Chem., 2016, 27, 1005-1012.

52 S. Bhattacharjee, J. Controlled Release, 2016, 235, 337-351.

53 L. Fan, R. Li, J. Pan, Z. Ding and J. Lin, Trends Plant Sci., 2015, 20, 388-397.

54 M. Faraco, C. Spelt, M. Bliek, W. Verweij, A. Hoshino, L. Espen, B. Prinsi, R. Jaarsma, E. Tarhan, A. H. de Boer, G.-P. Di Sansebastiano, R. Koes and F. M. Quattrocchio, Cell Rep., 2014, 6, 32-43.

55 C. Eisenach, R. Francisco and E. Martinoia, Curr. Biol., 2015, 25, R136.

56 K. Müntz, J. Exp. Bot., 2007, 58, 2391-2407.

57 T. Shimada, J. Takagi, T. Ichino, M. Shirakawa and I. Hara-Nishimura, Annu. Rev. Plant Biol., 2018, 69, 123-145. 58 K. Chen, H. Cai, H. Zhang, H. Zhu, Z. Gu, Q. Gong and K. Luo, Acta Biomater., 2019, 84, 339-355.

59 H. Shi, Y. Wang and R. Hua, Phys. Chem. Chem. Phys., 2015, 17, 30279-30291.

60 J. Ghitman, R. Stan, A. Ghebaur, S. Cecoltan, E. Vasile and H. Iovu, Polymers, 2018, 10, 579.

61 K. Hirano, H. Yoshida, K. Aya, M. Kawamura, M. Hayashi, T. Hobo, K. Sato-Izawa, H. Kitano, M. Ueguchi-Tanaka and M. Matsuoka, Mol. Plant, 2017, 10, 590-604.

62 P. Korinkova, V. Bazgier, J. Oklestkova, L. Rarova, M. Strnad and M. Kvasnica, Steroids, 2017, 127, 46-55.

63 B. V. Vardhini and N. A. Anjum, Front Environ. Sci., 2015, 2, 67. 
64 B. V. Vardhini, Plant Gene, 2017, 11, 70-89.

65 G. Sethi, M. K. Shanmugam, S. Warrier, M. Merarchi, F. Arfuso, A. P. Kumar and A. Bishayee, Nutrients, 2018, 10, 645.

66 R. Haag and F. Kratz, Angew. Chem., Int. Ed., 2006, 45, 1198-1215.

67 L. Zhang, Z. Cao, Y. Li, J.-R. Ella-Menye, T. Bai and S. Jiang, ACS Nano, 2012, 6, 6681-6686.

68 Y. C. Serrano, R. R. Fernandez, F. R. Pineda, L. T. S. Pelegrin, D. G. Fernandez and M. C. G. Cepero, Am. J. Biosci. Bioeng., 2015, 3, 197-202.
69 Z. Wang, Y. Jiang, X. Peng, S. Xu, H. Zhang, J. Gao and Z. Xi, Plant Growth Regul., 2017, 81, 455-466.

70 J. P. Quiñones, O. Brüggemann, J. Kjems, M. H. Shahavi and C. P. Covas, J. Agric. Food Chem., 2018, 66, 1612-1619.

71 K. Krukiewicz and J. K. Zak, Mater. Sci. Eng., C, 2016, 62, 927-942.

72 H. R. Allcock and N. L. Mozowich, Polym. Chem., 2012, 3, 578-590.

73 I. Teasdale and O. Brüggemann, Polyphosphazenes for Medical Applications, Smithers Rapra, 2014. 